This is a post-peer-review, pre-copyedit version of an article published in Journal of Community Health. The final authenticated version is available online at: http://dx.doi.org/10.1007/s10900020-00816-w"

\title{
Barriers and facilitators to implementing community outreach work, and inter- professional collaboration with regional partners
}

Mathieu Roy Ph.D. ${ }^{1-2}$, Étienne Lavoie-Trudeau M.T.S. ${ }^{3}$, Marie-Andrée Roy M.Sc. ${ }^{4}$, Irma Clapperton M.D., M.Sc., FRCPC ${ }^{4-5}$, Yves Couturier Ph.D. ${ }^{6-7}$, Julie Lane Ph.D., M.A. ${ }^{8-9}$, Linda Bibeau ${ }^{10}$, Myrthô Ouellette ${ }^{4}$, Maria Benkhalti, Ph.D. ${ }^{1}$, \& Chantal Camden Ph.D. ${ }^{3}$

${ }^{1}$ Health Technology and Social Services Assessment Unit, Eastern Townships Integrated University Health and Social Services Center, Sherbrooke, Quebec, Canada

${ }^{2}$ Department of Family Medicine and Emergency Medicine, Faculty of Medicine and

Health Sciences, Université de Sherbrooke, Sherbrooke, Quebec, Canada

${ }^{3}$ School of Rehabilitation, Faculty of Medicine and Health Sciences, Université de Sherbrooke, Sherbrooke, Quebec, Canada

${ }^{4}$ Eastern Townships Public Health Department, Eastern Townships Integrated University Health and Social Services Center, Sherbrooke, Quebec, Canada

${ }^{5}$ Department of Community Health Sciences, Faculty of Medicine and Health Sciences, Université de Sherbrooke, Sherbrooke, Quebec, Canada

${ }^{6}$ Sherbrooke University Hospital Research Centre, Eastern Townships Integrated University Health and Social Services Centre, Sherbrooke, Quebec, Canada

${ }^{7}$ School of Social Work, Faculty of Letters and Human Sciences, Université de Sherbrooke, Sherbrooke, Quebec, Canada

${ }^{8}$ RBC Academic Expertise Centre in Mental Health for Children, Teenagers, and Young Adults, Sherbrooke, Quebec, Canada 
This is a post-peer-review, pre-copyedit version of an article published in Journal of Community Health. The final authenticated version is available online at: http://dx.doi.org/10.1007/s10900020-00816-w"

${ }^{9}$ School of Education, Université de Sherbrooke, Sherbrooke, Quebec, Canada

${ }^{10}$ Avenir d'enfants, Boucherville, Quebec, Canada.

$\underline{\text { Please address correspondence to: }}$

Mathieu Roy, Ph.D., HTA Unit, CIUSSS de 1'Estrie - CHUS, 1036 Belvédère Sud, Sherbrooke (Quebec), Canada, J1H 4C4. Phone: 001-819-780-2220 (ext. 25445).

Email: mathieu.roy7@usherbrooke.ca

Word count of the abstract: 255

Word count of the main text: 3725

Number of pages: 24

Number of tables: 2

Conflict of interest: The authors declare no conflicts of interest

Acknowledgements: This work was co-funded by the CIUSSS de l'Estrie - CHUS

University Institute of Health and Social Services, local associations of inter-sectoral partners, the Collectif estrien 0-5 years, and by Avenir d'enfants. 


\begin{abstract}
Objective. Community outreach workers support individuals in accessing the health and community services they require through various forms of proximity approaches. Even though community outreach has been available in the province of Quebec (Canada) for the past 40 years, it is still difficult to implement and sustain, especially with families of young children. The aim of this study was to document barriers and facilitators to implementing community outreach practices, and to describe how such workers collaborate with sectoral (e.g. health care) and inter-sectoral (e.g. municipalities, community organizations, schools) partners. Methodology. We performed a content analysis on 55 scientific and grey literature documents, and transcriptions of 24 individual interviews and 3 focus groups with stakeholders including parents, community outreach workers, health care employees, and inter-sectoral partners. Results. This study reveals four categories of barriers and facilitators to the implementation of community outreach work (i.e. organizational factors, nature of the work and worker-related factors, family-related factors, external factors). With regards to collaboration, community outreach workers deal with various partners. Good inter-professional collaboration is achieved through positive interactions and communication, shared or co-developed activities for the families, co-intervention with families, and strategies to enhance role awareness and inter-sectoral meetings. Conclusion. Results highlighted that many factors interact and can either influence, positively or negatively, the opportunity to implement community outreach work. The collaborative practices identified may help to maximize facilitators and overcome barriers. Advocacy and a better understanding of how to integrate community outreach work within health services while maintaining the workers' flexibility are needed to sustain this practice.
\end{abstract}


Keywords: community outreach workers; proximity approaches; social intervention;

health promotion; community 


\section{Introduction}

While community outreach work is recognized as an effective social practice to reach persons in vulnerable situations (Andersson, 2013; Denis, 2017; Giger \& Davidhizar, 2007), this work is not widely documented, especially with families of children aged 0 to 5 years old. In the province of Quebec (Canada), partners fostering early childhood health have implemented community outreach work. Most families served by community outreach workers have limited economic capabilities and low levels of empowerment to improve their economic, psychosocial, and cultural conditions (Castel, 2000; Spiers, 2005). All these factors challenge their abilities to access services (Beadle, 2009). These families are likely to disaffiliate from existing structures and are often hard-to-reach (Castel, 2000). Community outreach workers act like a relay between the street (i.e. the community) and the resources (e.g. care or services; Andersson, 2013) to engage with these families (Coe, Gibson, Spencer, \& Stuttaford, 2008; Santis et al., 2013; Statham, 2004). Families supported by community outreach workers have reported higher self-esteem and less depression than those without support (Navaie-Waliser, Martin, Tessaro, Campbell \& Cross, 2000).

Community outreach work is recognized as being effective with families at improving health and well-being, but this social practice has been difficult to sustain over time due to many challenges or barriers (Atherton, 2012; Decker, Bynum, McDevitt, Farrell \& Varano, 2008). Examples of implementation barriers relate to high staff turnover, and a lack of understanding between different practitioners (Bovarnick, McNeish, \& Pearce, 2016; Devaney, 2008; Schram \& Silverman, 2012). Collaboration and information sharing between traditional health organizations and community workers 
may also be challenging (Purcal, Muir, Patulny, Thomson, Flaxman, 2011). Collaboration is, however, crucial to implement community outreach practices. Collaboration between different partners and families can be fostered through a focus on communication (i.e. increasing knowledge about families served while simultaneously constructing a relationship between partners), collaboration (i.e. networking, coordination, and services integration), and creation of opportunities to includes families (Blakemore et al., 2012; Peacock, Issel, Townsell, Chapple-McGruder, \& Handler, 2011; Winkworth, \& White, 2011; Winkworth, McArthur, Layton, \& Thomson, 2010).

The main objective of this study was to better understand the factors influencing the implementation of community outreach work for children and families in vulnerable circumstances in the Eastern Townships, Quebec (Canada). Co-developed with an advisory committee, our specific objectives were to: 1) document barriers and facilitators to implementing community outreach work, and 2) describe how community outreach workers collaborate with sectoral (e.g. health care) and inter-sectoral (e.g. municipalities, community organizations, schools) partners.

\section{Methods}

\section{Setting}

The Eastern Townships are located in the southeastern part of the province of Quebec (Canada). This region is one of 18 health areas in Quebec and includes a mix of urban, semi-urban, and rural areas. The population of this area is approximately 500,000 people (Statistics Canada, 2016). The city of Sherbrooke is Quebec's $6^{\text {th }}$ largest city with 170,000 people, and is predominantly French-speaking (93.4\%; Statistics Canada, 2016).

\section{Study design}


We used an exploratory qualitative design (Trudel, Simard, \& Vonarx, 2006), gathering and analysing three sources of qualitative data: 1) scientific and grey literature ( $n=55$ documents; e.g. community journals, activity reports, reference frameworks), 2) individual interviews $(n=24)$, and 3$)$ three focus groups ( $n=19$ participants). Ethics approval was received from the CIUSSS Estrie-CHUS. An advisory committee composed of researchers, public health representatives, community outreach workers, and parents co-developed the research proposal and questionnaires, provided guidance during the study, and helped interpret the results.

\section{Participant recruitment process}

Four groups of participants were recruited: 1) community outreach workers, 2) parents receiving community outreach support, 3) health care employees, and 4) intersectoral partners (e.g. community organizations, early childhood centres, and municipal services collaborating with outreach workers). Recruitment was opportunistic and based on a snowball sampling method. Efforts were made to ensure the greatest diversity of participants, especially for families (i.e. single parents, parents from immigrant families, parents who were English speakers, families from rural, semi-rural and urban areas).

\section{Data collection process}

Documents were collected from December 2018 to April 2019 from partners, and through emails to community outreach workers. Interviews were conducted from April to June 2019, with focus groups occurring in June 2019. Individual interviews lasted up to 75 minutes and focus groups lasted approximately 90 minutes. For the interviews and focus groups we used a similar semi-structured interview guide built by the research team and validated by the advisory committee. Themes covered included questions about 
outreach work barriers, facilitators, and collaborative work. Questions were based on available grey literature and experiential knowledge of the advisory committee.

\section{Data analysis}

All data (i.e. document analysis, interviews, focus groups) were analyzed with a four-step content analysis procedure (Krippendorff, 2003) performed by a research assistant with a social work background. The $1^{\text {st }}$ step was a double listening (or reading) of the raw data. The $2^{\text {nd }}$ step was a data coding procedure organized in 'axial' and 'selective' stages. The axial stage categorized the data whereas the selective stage

organized the categories. The $3^{\text {rd }}$ step was data treatment, which included a semantic analysis. The $4^{\text {th }}$ and final step was data interpretation where themes and sub-themes were identified along with quotes to support those themes. Quotes exemplifying identified themes were loosely translated from French to English for the purposes of reporting here. Consultation with the research team, including partners, occurred at all steps to ensure validity in the analysis and interpretation processes.

\section{Results}

\section{Participants and data sources}

Table 1 reports the numbers of participants involved in the interviews and focus groups. Table 2 highlights barriers and facilitators to community outreach work, and determinants of good inter-professional collaboration between these workers and other regional partners. These themes are discussed in more detail below.

\section{[Insert Table 2]}

\section{Barriers and facilitators to implementation of community outreach work}


Participants described four barriers and facilitators that affected the implementation of community outreach work and interventions: 1) organizational factors, 2) nature of the work and worker-related factors, 3) family-related factors, and 4) external factors.

\section{Organizational factors}

Collaborative work and communication with partner organizations were perceived to foster good quality of community outreach work by focussing on problem-solving and developing unique trajectories of services for specific families. Participants mentioned that community outreach work was easier to implement when the management of the partner organization was supportive of this type of work (e.g. when directors are part of committees overseeing community outreach workers). Clear accountability and detailed (statistical) reports also were perceived as facilitating the implementation of this practice. Finally, participants felt it was important that the structure around community outreach workers was non-bureaucratic and non-hierarchical, to allow for job flexibility within a clear mandate:

"The thing that helps my work, among others, is to have a diversified committee who
supervise me. This helps me a lot. It gives me access to different spheres of the community.
It's a win. They care about my mental health; they give me winning work conditions with
the salary and social advantages." (community outreach worker)

When the factors mentioned above were not present, community outreach work was reported as being difficult to implement. For instance, lack of knowledge about the nature of community outreach work, misconceptions about the work itself, and feelings of competition with other organizations were perceived as barriers to implementation. Community workers felt that they needed to be the ones to initiate collaboration and didn't feel that others approached them for collaboration, limiting opportunities for real partnerships, especially with larger organizations. Community outreach workers 
sometimes felt a lack of empowerment when faced with traditional structures and long waiting lists, where they believed that the needs of the families they represented were not often seen as a priority.

\section{Nature of the work and worker-related factors}

Participants who were knowledgeable of community outreach work reported that the nature of the work allowed workers to be more respectful of families, including individual families' particular rhythm. The nature of the work allowed workers to experience a different role with families, compared to other health care professionals. Since community outreach workers lived in the same neighborhoods as the families they served, they knew their culture, which was considered an important facilitator when working with them. The workers' close connections with families, combined with their academic knowledge, was mentioned as being essential to facilitate the implementation of interventions:

"It's important that the community outreach worker have a good drive and a minimum of boldness. Before being included in a new environment, there is an uncomfortable zone in what we do. I'll have to live with that and take the ball. He plays an important role in this facility. He has to understand the timing to intervention." (community outreach worker)

To successfully facilitate community outreach work, workers had to be individuals who presented themselves as being available, flexible, neutral, non-threatening, stable and present to meet with and interact with families. They needed to have extensive knowledge of the family's neighbourhood and its resources. Being available by cell phone helped increase their availability, and access to funds supported their participation in unplanned events which required additional monies. To reduce isolation felt by community workers (perceived as a barrier to implementation of this type of work), opportunities to meet other community outreach workers were noted as being supportive 
to the workers themselves. Community outreach workers were encouraged to keep written notes of their work to help sustain practices and improve continuity:

"I realized that I was leaving too little trace on the way I work, even if it's important. The transfer [to a new community outreach worker] will be crucial, including the way we will transfer all that knowledge." (community outreach worker)

Perceived barriers to the implementation of community outreach work included lack of support, work conditions, lack of training, and the high emotional demands to the work. Without support, worker burnouts were frequent and lead to a high rate of worker turnover. Pressures on community workers also included a high number of community needs and demands, and the long duration of time needed to connect with families. Travelling time, especially in rural areas, was also a barrier to implementation, as workers had to cover large service areas. Another job constraint related to accountability issues was the need for quantitative indicators to support their work. This was a challenge, given that the work was more suited to qualitative indicators (e.g. relationships with families, building trust and opportunities with them). Confidentiality issues of referral documents from partner organizations also limited accountability, since it was often not possible to follow families through the system when they moved to other neighbourhoods.

"I find families very isolated. They should be stowed with us [health care team] or together or whatever... In the end, they are isolated. You [know] my hard situation that I told you two minutes ago? She was living alone at her home, with no team to vent. Me, I always go for a team for that, a clinic supervisor. You can easily burn yourself out, because you can't be objective. They are alone, they go in families 'home they don't know [it can happen catastrophes]. For us, we have emergency phone number to call and they don't." (health care partner)

\section{Family-related factors}

Good relationships between families and community workers, as well as recognition of the worker's role, were perceived to facilitate the work. Success stories, 
such as when a community outreach worker was successful in helping a child or a family access services, were believed to increase the likelihood of families accepting being referred to other health care partners. These families in turn became champions and facilitated community outreach work, as they positively talked about this approach and connected the community with the workers.

"Yes, it's easier, because I have families that I accompany who come with others, so I
create link[s] with them to. There are always needs at every level." (community outreach
worker)

Barriers to community outreach work relating to families included the difficulties in mobilizing communities, especially when there were multiple cultural communities and when cultural expectations and languages presented challenges to the intervention. It is possible that some families could begin to feel over dependent with community outreach workers, creating a sense of comfort for workers but limiting workers' ability to support families and contribute to their empowerment. Some participants perceived it could increase the marginalization of families, which is contradictory to the main goal of community work.

"The language is a barrier. Even if the community outreach worker speaks English. His English must be... not necessarily good, but from the street, a slang to create new links with culture, because it's really a tight community [the English community]." (community outreach worker)

\section{External factors}

It was reported by participants that the change in seasons and weather conditions were major barriers for community outreach work, due to the difficulty in reaching families during the winter season, and activities sometimes needed be cancelled because of bad weather. Also, the political context was mentioned, in the way that a period of 
austerity could lead to a decrease in hiring of community outreach workers, and reduced financing overall.

"The climate influences where people will be and their habits. It's much easier to create links in summer, rather than in winter. The start of the school year is complex, full of restructuring, organization and a lot of fees. In the winter, for January and after, it begins to be morally difficult. More depressions, it's a dark period. In April, it's more about the electricity cuts. It's cyclic, there is a tendency". (community outreach worker)

\section{Inter-professional collaboration with regional partners}

Four determinants of good inter-professional collaboration with regional partners were identified from the data analyzed: 1) positive interaction and communication, 2) shared and co-developed activities for families, 3) co-intervention with families, and 4) strategies to enhance role awareness and inter-sectoral meetings.

\section{Positive interaction and communication}

Worker participants identified many ways of communicating with partners and families including by phone, email, in person, and using text messages and social networks. They also used inter-sectoral meetings to communicate between them. Also, some relational factors helped foster collaboration, including trusting other health care professionals, creating and maintaining good contacts and communication with other organizations, developing and maintaining complicity, and finding ways to share information without breaking confidentiality. Specifically, to increase the quality and effectiveness of relationships with partners, it is important for community outreach workers to understand and endeavour to work with partners' institutional limits.

"I try to put in the picture speakers of what is going on at the neighborhood table, because they aren't on the coordination committee. [...] I try to maintain this consciousness that it's us, and that we are a collective." (Community partner)

\section{Shared and co-developed activities for families}


Community outreach workers collaborate with others to ensure families participate in organized activities, with community outreach workers invited to partners' activities and vice-versa. Collaborative work was perceived to be important when designing relevant community activities, for families, when disseminating information about the activities, and when connecting families with relevant services as needed. This collaboration was felt to contribute to the realization of partners' activities, to the development of new activities and projects together, and to sharing information about upcoming activities.

"I work with community outreach workers on the development of community projects. Eventually, we will finish a project on the emotions, for the prevention of the development of socio-affective difficulties for children and how to deal with emotions." (health care partners)

\section{Co-intervention with families}

Collaboration among community outreach workers and other health care workers was perceived to be key to best support families. Workers with different backgrounds can come together to adopt a complementary perspective, to ensure a global intervention approach to help families. Since different workers often work with the same families, sharing a common vision and understanding of the families' needs was perceived to facilitate collaboration. It was felt that to be effective, collaborative work needed to be based on trust between the partners and community outreach workers. This trust could facilitate collaboration and the implementation of the work in many different ways, such as giving access to a local in the partners installations. Community outreach workers were also perceived to have resources they could share to support this collaboration, and function, for instance, as a resource directory, to inform partners about the resources available in the community. To ensure cost-effective collaboration, many partners 
mentioned the intensity of the collaboration should vary according to the needs of the children and families.

\begin{abstract}
"About the collaborative work, I really think that we have to work together. There are certain times that partners have been hurt by the community outreach worker... They were working on things with their clients, and the community outreach worker was working on things that contradict the work of partners. The partner felt incompetent after that. It's important that we work together in a common vision, we're targeting this, we are going on this way. It's not necessary to have all the objectives in common, but at least some. (health care partner)
\end{abstract}

\title{
Strategies to enhance role awareness and inter-sectoral meetings
}

Being known by partners was perceived to be important for community outreach workers, to facilitate collaboration with others. They thus needed to present themselves, to attend partners' team meetings, distribute flyers to partners, and to receive newsletters to stay informed of community happenings. Most community workers reported participating, along with a number of partners in round table discussions, committees, or meetings on different subjects related to children and families. Community outreach workers have the potential to enhance these discussions because of their experiences 'on the ground' in neighbourhoods and communities. Also, when they successfully collaborate, they are able to be part of the development of intervention plans that children or parents need (for example individualized service plan for health care services) that focus on interdisciplinary practices. Finally, outreach workers can participate in annual general meetings and/or meetings of the boards of directors of partner organizations or boards of directors who supervise community outreach workers, all to enhance awareness of their role, and which were described as being helpful:

"The community outreach worker is on the committee [for the children of the region]. It means that she can bring the reality of the terrain for us in the region. What she lived. She is on committees who take into consideration families. She came at the forum [about the trajectory services] to know more about partners and improving their references [...] Her presence on round table discussions permits her to bring the 
anglophone reality and the family realities. [...] She brings her expertise of community

outreach worker directly from intervention with these families. " (community partner)

\section{Discussion}

This study sought to explore: 1) barriers and facilitators to implementing community outreach work, and 2) determinants of good inter-professional collaboration with regional partners. Results were consistent between three sources of data including grey literature, individual interviews, and focus groups with multiple stakeholders including both sectoral and inter-sectoral partners. Our results demonstrate that it is crucial for community outreach work to be based on collaborative work with local partners to ensure successful implementation, as previously reported (Stout et al., 1998). Community outreach work has been previously reported as being limited by different barriers related to funding and organizational constraints (Bovarnick et al., 2016; Devaney, 2008; Purcal et al., 2011; Schram \& Silverman, 2012). However, our results also indicate that some barriers to successful community outreach implementation relate to the nature of the work itself (i.e. community outreach workers' roles and characteristics). Results from our study highlight that community outreach work is still difficult to clearly articulate, which provides workers with considerable flexibility to respond to families' needs, but which also challenge implementation and collaboration within the health care system including community activities. This lack of clarification may lead to misunderstanding and mistrust between community outreach workers and potential partners, but also with families. Barriers related to families and the nature of community outreach have been previously discussed in the literature (Avis, Bulman, \& Leighton,2006), but results from this study highlight how community outreach workers attempt to navigate the system to transform these barriers into facilitators, such as by 
building on success stories with families who then, in turn, become champions and advocate for them in the community. Themes identified here also highlight the difficult contexts in which community outreach workers often work, including cultural, organizational, and funding contexts, all of which occur alongside what is often highly emotionally-demanding work. Solutions are needed not only to sustain the implementation of this practice, but also to support the workers, such as providing peer supports and facilitating connections with traditional health care structures. Our study shows that collaboration is key, not only among community outreach workers to provide support, and with the families to gradually increase their empowerment level, but also with other partners, where they use different collaboration strategies to implement community work (e.g. communication, collaboration, and creation of opportunities for families; Blakemore et al., 2012).

\section{Limits}

Limitations of our study include limited external validity and generalization of results, since the study was conducted in a single health region. Despite this, however, individuals who participated were from different health care districts. It is also important to note that half of the parent participants interviewed weren't overly talkative in the in the focus groups. This could be explained by the fact that some needed to be assisted by the community outreach worker during the interview because of a language barrier and potential mistrust vis-a-vis the interviewer, who was perceived to be from a health care organization. As a consequence, the views of community outreach workers and/or partners may be over-represented compared to parents.

\section{Conclusion}


Community outreach workers have a great role to play within traditional health care services to help health care organizations achieve their missions and mandates, especially with regards to populational health and health equity. Collaboration between community outreach work and traditional health care services should be strengthened, to foster interprofessional work with, and for, families and children in vulnerable situations. The scope of practice of community outreach workers is different from other psycho-social professionals, principally because they live in the communities of the families they serve. Community outreach workers can enhance any health care system trying to achieve health equity, but the importance of their work needs to be understood, recognized, and valued. Workers also need to be supported if this type of proximity practice is to be sustained. 


\section{References}

Andersson, B. (2013). Finding ways to the hard to reach-considerations on the content and concept of outreach work. European Journal of Social Work, 16, 171-186. https://doi-org.ezproxy.usherbrooke.ca/10.1080/13691457.2011.618118

Avis, M., Bulman, D., \& Leighton, P. (2006). Factors affecting participation in Sure Start programmes: A qualitative investigation of parents' views. Health and Social Care in the Community, 15(3): 203-11. https://doi.org/10.1111/j.1365-2524.2006.00673.x

Atherton, G. (2012). AccessHE: can collaborative outreach work continue in London after Aimhigher? Widening Participation and Lifelong Learning, 13(1), 93-100. https://doi.org/10.5456/WPLL.13.S.93

Beadle, S. (2009). Complex solutions for complex needs: Towards holistic and collaborative practice. Youth Studies Australia, 28(1), 21.

Blakemore, T., Crofts, P., Esler, M., Evans, J., Geggie, J., Kerr, T., et al. (2012). Outreach and integration in family services: Enhancing the capacity of the NGO sector-Colloquium Report, 2011. University of Newcastle, Newcastle, Australia. Family Action Centre University of Newcastle University Drive Callaghan NSW, 2308. 
Bovarnick, S., McNeish, D., \& Pearce, J.J. (2016). Outreach work: child sexual exploitation: a rapid evidence assessment. University of Bedfordshire.

Castel, R. (2000). The Roads to Disaffiliation: Insecure Work and Vulnerable Relationships. International Journal of Urban \& Regional Research, 24(3), 519. https://doi.org/10.1111/1468-2427.00262

Coe, C., Gibson, A., Spencer, N., \& Stuttaford, M. (2008). Sure Start: Voices of the hardto-reach. Child: Care, Health and Development, 34(4): 447-53. https://doi.org/10.1111/j.1365-2214.2008.00816.x

Decker, S.H., Bynum, T.S., McDevitt, J., Farrell, A., \& Varano, S.P. (2008). Street outreach workers: Best practices and lessons learned. Boston, MA: Northeastern University, Institute on Race \& Justice.

Denis, V., (2017). Efficiency of the Action: «Community outreach worker » to join disadvantaged families with children between 0-5: Synthesis of results coming from the analysis of local partners grouping' reports evaluation. Avenir d'enfants.

Devaney, J. (2008). Interprofessional working in child protection with families with long term and complex needs. Child Abuse Review, 17: 242-61. https://doi.org/10.1002/car.1024

Giger, J. N., \& Davidhizar, R. (2007). Promoting culturally appropriate interventions among vulnerable populations. In A. Nyamathi \& D. Koniak-Griffin (Eds.), Annual review of nursing research, 2007: Vulnerable populations. (Vol. 25, pp. 293-316). New York, NY: Springer Publishing Company.

Krippendorff, K. (2003). Content analysis: An introduction to its methodology. Thousand Oaks, CA: Sage Publications. 
Navaie-Waliser, M., Martin, S.L., Tessaro, I., Campbell, M.K., \& Cross, A.W. (2000). Social support and psychological functioning among high-risk mothers: The impact of baby love maternal outreach worker program. Public Health Nursing, 17, 280291. https://doi-org.ezproxy.usherbrooke.ca/10.1046/j.1525-1446.2000.00280.x

Peacock, N., Issel, L. M., Townsell, S. J., Chapple-McGruder, T., \& Handler, A. (2011). An innovative method to involve community health workers as partners in evaluation research. American journal of public health, 101(12), 2275-2280. 10.2105/AJPH.2011.300263

Purcal, C., Muir, K., Patulny, R., Thomson, C., \& Flaxman, S. (2011). Does partnership funding improve coordination and collaboration among early childhood services? Experiences from the Communities for Children programme. Child \& Family Social Work, 16(4), 474-484. https://doi-org.ezproxy.usherbrooke.ca/10.1111/j.13652206.2011.00766.x.

Santis, R., Hidalgo, C.G., Jaramillo, A., Hayden, V., Armijo, I., \& Lasagna, A. (2013). A family outreach intervention for engaging young out-of-treatment drug users: Preversus post-treatment comparison. Journal of Substance Abuse Treatment, 44, 6170. https://doi-org.ezproxy.usherbrooke.ca/10.1016/j.jsat.2012.03.003

Schram, S. F., \& Silverman, B. (2012). The end of social work: Neoliberalizing social policy implementation. Critical Policy Studies, 6(2), 128-145. https://doi.org/10.1080/19460171.2012.689734

Spiers, J.A. (2005). A concept analysis of vulnerability. The Essential Concepts of Nursing: Building Blocks for Practice, 331. 
Statham, J. (2004). Effective services to support children in special circumstances. Child:

Care, Health and Development, 30(6): 589-98. 10.1111/j.1365-2214.2004.00472.x

Statistics Canada (2016). Census Profile, 2016 Census. Government of Canada.

Stout, J.W., White, L.C., Rogers, L.T., McRorie, T., Morray, B., Miller-Ratcliffe, M., et al. (1998). The asthma outreach project: A promising approach to comprehensive asthma management. Journal of Asthma. 35, 119-127

Trudel, L., Simard, C., \& Vonarx, N. (2006). Is qualitative research necessary exploratory? Qualitative Researches, 5, 38-55.

Winkworth, G. \& White, M. (2011) Report to the ACT Human Rights Commission on Structures and Organisational Arrangements to Support Reform in ACT Youth Justice, ACT Government.

Winkworth, G., McArthur, M., Layton M., \& Thomson, L. (2010). Someone to check in on me: Social capital, social support and vulnerable parents with very young children in the Australian Capital Territory. Child and Family Social Work 15(2), 206-215. https://doi.org/10.1111/j.1365-2206.2009.00660.x 
Table 1: Numbers of stakeholders participating in interviews and focus groups

\begin{tabular}{|c|c|c|c|c|c|c|c|}
\hline \multirow{3}{*}{ Data source } & \multicolumn{6}{|c|}{ Stakeholder participants } & \multirow{3}{*}{$\begin{array}{l}\text { Total } \\
\text { Number }\end{array}$} \\
\hline & \multirow{2}{*}{$\begin{array}{c}\text { Community } \\
\text { outreach } \\
\text { workers }\end{array}$} & \multirow[t]{2}{*}{ Parents } & \multirow{2}{*}{$\begin{array}{c}\text { Health } \\
\text { care } \\
\text { employees }\end{array}$} & \multicolumn{3}{|c|}{ Inter-sectoral partners } & \\
\hline & & & & $\begin{array}{c}\text { Community } \\
\text { Organizations }\end{array}$ & Schools & Municipal & \\
\hline $\begin{array}{l}\text { Individual } \\
\text { interviews }\end{array}$ & 5 & 9 & 5 & 3 & 2 & - & 24 \\
\hline Focus groups & 3 & 7 & 3 & 4 & 1 & 2 & 20 \\
\hline
\end{tabular}


Table 2. Themes and sub-themes identified through analysis of grey literature, interviews and focus groups

\begin{tabular}{|c|c|c|c|c|}
\hline Themes & Sub-themes & $\begin{array}{l}\text { Document } \\
\text { analysis }\end{array}$ & Interviews & $\begin{array}{l}\text { Focus } \\
\text { groups }\end{array}$ \\
\hline \multirow{4}{*}{$\begin{array}{lr}\text { 1) Barriers and } \\
\text { facilitators } \\
\text { implement } \\
\text { community outreach } \\
\text { work }\end{array}$} & Organizational factors & $\mathrm{X}$ & $\mathrm{X}$ & $\mathrm{X}$ \\
\hline & $\begin{array}{l}\text { Nature of the work and workers-related } \\
\text { factors } 0\end{array}$ & $X$ & $X$ & $\mathrm{X}$ \\
\hline & Family-related factors & $\mathrm{X}$ & $\mathrm{X}$ & - \\
\hline & External factors & $\mathrm{X}$ & $\mathrm{X}$ & - \\
\hline \multirow{4}{*}{$\begin{array}{l}\text { 2) Determinants of } \\
\text { good inter- } \\
\text { professional } \\
\text { collaboration }\end{array}$} & Positive interaction and communication & - & $\mathrm{X}$ & $\mathrm{X}$ \\
\hline & $\begin{array}{l}\text { Shared and co-constructed activities for } \\
\text { families }\end{array}$ & - & $\mathrm{X}$ & $\mathrm{X}$ \\
\hline & Co-intervention with families & - & $\mathrm{X}$ & $\mathrm{X}$ \\
\hline & $\begin{array}{l}\text { Strategies to be known and inter-sectoral } \\
\text { meetings }\end{array}$ & - & $\mathrm{X}$ & $\mathrm{X}$ \\
\hline
\end{tabular}

